\title{
Jogo tradicional-popular e aprendizagem: uma análise teórica das comunicações dos jogadores*
}

* Este artigo é resultado da dissertação de mestrado intitulada "As aprendizagens interativas e cognitivas em jogos tradicionais-populares nas aulas de educação física", de autoria de Rodrigo Wanderley de Sousa Cruz, sob a orientação do professor Dr. Pierre Normando Gomes-daSilva, defendida em 23/5/2014, no Programa de Pós-Graduação em Educação da Universidade Federal da Paraíba.

Instituto de Educação Superior da Paraíba (Iesp), João Pessoa, Paraíba, Brasil.

E-mail: rodrigowcruz@ig. com.br

II Mestre em Educação pela Universidade Federal da Paraíba (UFPB), João Pessoa, Paraíba, Brasil.

III Programa de Pós-Graduação em Educação Física Associado à Universidade de Pernambuco/Universidade Federal da Paraíba, João Pessoa, Paraíba, Brasil.

E-mail: pierrenormandogomes dasilva@gmail.com

IV Doutor em Educação pela Universidade Federal do Rio Grande do Norte (UFRN), Natal, Rio Grande do Norte, Brasil.

v Programa de Pós-Graduação em Educação Física da Universidade Federal de Santa Maria (UFSM), Santa Maria, Rio Grande do Sul, Brasil. E-mail: ribasjfm@hotmail.com

vi Doutor em Educação Física pela Universidade Estadual de Campinas (Unicamp), Campinas, São Paulo, Brasil.

\author{
Rodrigo Wanderley Sousa Cruz ${ }^{\mathrm{I}}$ II \\ Pierre Normando Gomes-da-Silva ${ }^{\text {III, IV }}$ \\ João Francisco Magno Ribas v, vi
}

http://dx.doi.org/10.1590/S2176-6681/347013683

\section{Resumo}

Objetiva estabelecer dupla abordagem teórica sobre a comunicação no jogo. Para tal, propomos a praxiologia motriz, com o fim de analisar a lógica interna do jogo, e a pedagogia da corporeidade, com sua analítica existencial do movimento, para compreender o modo de agir dos jogadores. Na especificidade das abordagens, o jogo tradicional-popular recebeu uma análise objetivo-funcional e subjetivo-cultural das ações dos jogadores em sua interação com o ambiente do jogo. Assim, neste ensaio analíticopropositivo, o jogo foi apresentado como situação de movimento privilegiada para os processos de ensino-aprendizagem na escola.

Palavras-chave: jogo; aprendizagem; comunicação; educação física; cultura. 


\section{Abstract \\ Traditional folk games and learning: a theoretical analysis of players' communications}

This research aims to establish a double theoretical approach about communication in games. For this purpose, we focus on the driving praxiology, in order to analyze the internal logic of the game, and the pedagogy of embodiment, with its existential analytic movement, to understand the players' mode of action. In the specificity of approaches, the traditional-popular game received a functional-objective and culturalsubjective analysis of the players' actions in their interaction with the game environment. Thus, in this analytical and propositional essay, game was presented as a privileged motion situation for the teaching and learning processes at school.

Keywords: game; learning; communication; Physical Education; culture.

\section{Considerações iniciais}

Esta investigação teórica se localiza no universo das pesquisas do Laboratório de Estudos e Pesquisas em Corporeidade, Cultura e Educação (Lepec) $)^{1}$ da Universidade Federal da Paraíba (UFPB), que tem como matriz epistêmica a pedagogia da corporeidade (Gomes-da-Silva, 2001; 2011; 2012a; 2014), cujo objetivo principal é investigar/criar práticas pedagógicas para diferentes públicos e contextos, tomando a situação de movimento como a instância básica para o conhecimento e a transformação de si e do mundo, na perspectiva da interação, implicação e integração.

Esta pesquisa também é fruto da parceria com o Grupo de Estudos em Lazer e Formação de Professores (GPELF) ${ }^{2}$ da Universidade Federal de Santa Maria (UFSM), com o qual temos desenvolvido investigações sobre o jogo na educação, particularmente sob o enfoque teórico da praxiologia motriz de Pierre Parlebas (2001). Destacamos algumas pesquisas sobre os processos comunicativos nos jogos tradicionais, em que tomamos as jogadas como produtoras de sentido, portanto, uma prática de linguagem (Soares; Ribas; Gomes-da-Silva, 2012; Gomes-da-Silva, 2012a; 2012b; Sousa Cruz, 2014; Sousa Cruz et al., 2015).

Os jogos tradicionais representam um fenômeno socialmente importante porque pertencem à cultura popular, constituem-se num patrimônio imaterial da humanidade. São jogos que, mesmo não tendo um pertencimento institucional (federações ou confederações) ou organização e sistematização de suas regras, permanecem na história, atravessam séculos e regiões. Por isso mesmo, têm despertado o interesse de diferentes pesquisadores das mais distintas áreas, com destaque para os clássicos: na psicologia com Piaget (1990; 1994) e Vygotsky (1996), na psicanálise com Winnicott (1975), na história com Huizinga (1996), na sociologia com Caillois (1990), na educação infantil com Chateau (1987), na pedagogia com Brougére (2002) e na educação física com Parlebas (2001). Interessamo-nos,

\footnotetext{
Criado em março de 2006, pertence ao Grupo de Estudos e Pesquisas em Corporeidade, Cultura e Educação (Gepec/ CNPq). Esse grupo tem endereço no laboratório pertencente ao Departamento de Educação Física e ao Núcleo de Ciências do Movimento Humano (Centro de Ciências da Saúde-CCS-UFPB/Campus I). A linha de pesquisa é a pedagogia da corporeidade, coordenada pelo prof. Dr. Pierre Normando Gomes-daSilva, a qual é constituída por três sublinhas de pesquisa (aprendizagem complexa, educação/saúde integrativa e formação de professores), operacionalizadas por cinco grupos de trabalho: jogos sensoriais, jogos ambientais, jogos tradicionais e esportivos, brincar do bebê e brincar do velho.

2 O grupo de pesquisa formou-se no início de 2006 em decorrência de ações investigativas de diferentes pesquisadores do Centro de Educação Física e Desportos da Universidade Federal de Santa Maria (UFSM), que têm em comum a confluência de suas temáticas foco de pesquisa. O grupo é coordenado pelos professores Dr. João Francisco Magno Ribas e Dra. Elizara Carolina Marin. Desenvolve suas atividades com o objetivo de pesquisar as manifestações lúdicas, de lazer e de esportes em diferentes contextos socioculturais; as diferentes práticas escolares no contexto de escolas de educação básica dos sistemas públicos de ensino; a organização e o desenvolvimento dos processos de formação de professores.
} 
em particular, pelos estudos de Pierre Parlebas, porque são investigações sobre a lógica interna dos jogos: as classificações dos jogos, a conduta dos jogadores, os mecanismos de codificação criados e as ações práxicas realizadas (Parlebas, 2013).

Dessa forma, aproximados pela pedagogia da corporeidade e pela praxiologia motriz, compreendemos o jogo tradicional como uma situação de movimento cultural, passível de análise da circunstância comunicativa, na qual os jogadores semiotizam o ambiente para agir, e como produtora de subjetividade, formando o jogador em sua percepção e sensibilidade (Gomes-da-Silva, 2014), haja vista que "qualquer pessoa ao intervir no jogo tradicional se impregna de símbolos, signos e códigos que põem em ações traços culturais representativos da sociedade na qual se vive. Entrar em jogo é entrar na sociedade" (Lavega, 2013, p. 287).

Estudos recentes vêm sendo realizados com o intuito de defender a relevância do jogo como um elemento indispensável à educação, identificando suas potencialidades e possibilidades de intervenção e de aprendizagem (Sousa Cruz et al., 2015; Carvalho; Oliveira, 2014; Pavía, 2014; Marin; Ribas, 2013; Lavega, 2013; Sousa Cruz, 2014; Ribas, 2005; 2008; Marin et al., 2012; Gomes-da-Silva; Antério; Schulze; Cruz, 2014; Gomes-da-Silva, 2005; 2006; 2011; 2012a; 2012b; Murcia, 2005; Ortiz, 2005; Santos, 2012; Soares; Gomes-da-Silva; Ribas, 2012; Freire, 2002; 2005; Freire; Scaglia, 2007). Esses autores, entre outros, possibilitam discutir o jogo como manifestação cultural instigante, possível de ser implicada na escola como espaço de aprendizagens múltiplas para quem o vivencia. Contudo, desde Froebel (1782-1859), com a criação dos jardins de infância, estamos engatinhando nas possibilidades educativas do jogo.

Aproximamo-nos da reflexão de Santos (2012), para o qual, se a escola é um ambiente de conhecimento científico e cultural, então não se pode considerar o jogo apenas como um recurso divertido ou prazeroso para os educandos. Seria simplista pensar que ele está presente nas salas de aula somente para deleite de alunos, incentivo à aprendizagem e motivação aos professores.

Inquietamo-nos com o modo de tratar o jogo na escola, sobretudo o tradicional-popular nas aulas de educação física, por compreender seu valor educativo e cultural na aprendizagem de quem joga. Evidentemente, há vários elementos compondo a situação, por exemplo, a forma como o jogo está sendo vivenciado (regras diretivas ou com variações), o campo (ginásio, pátio ou terreno), os objetos utilizados (forma, tamanho, textura e peso) e, principalmente, as ações dos jogadores durante o jogo (interação com os demais jogadores e com o meio). Essa pluralidade no contexto do jogo só é possível porque ele "está além de sua caracterização de jogo e somente poderá ser verificado como manifestação de jogo quando revelado no ato de jogar" (Reverdito; Scaglia, 2009, p. 145).

Interessamo-nos pelo jogo na perspectiva de movimentos corporais, habilidades motoras, tarefas técnico-táticas e melhoria no rendimento cognitivo e motor, porque atentamos para a experiência existencial do jogar, para a qual o jogador é convocado a agir e interagir, ver-se formado 
e transformado, na medida em que forma e transforma a situação (Gomesda-Silva, 2005; 2006; 2012b). Enfocamos o jogo no seu caráter educativo (Freire, 2005; 2007; Chateau, 1987), quer dizer, na aprendizagem com que o jogador atua, compreende e se relaciona com o mundo do jogo.

Mais do que simples divertimento ou recurso pedagógico, compreendemos o jogo pela pedagogia da corporeidade (Gomes-da-Silva, 2011; 2014; Gomes-da-Silva et al., 2014) como produção de sentido, como crescimento e multiplicação de signos mediando os sujeitos com o mundo, portanto, uma prática de linguagem. Jogo é linguagem na medida que é uma prática humana e social de demarcar, codificar e significar, resultante de inúmeras interações e ações na circunstância. Desse modo, a linguagem é responsável por organizar as condutas, porque oferece uma significação do entorno e não se restringe à codificação verbal, mas à mediação estabelecida com o meio, logo, pode ajudar o jogador a melhorar sua prática.

Este trabalho investigativo nos possibilita concatenar e oferecer uma dupla compreensão do jogo, tanto pelo campo da comunicação humana, uma gramática vivida na circunstância lúdica em meio ao fluxo biossemiótico de informações, quanto como produtor de subjetividade e formação humana existencial.

Por isso analisamos as situações de movimento tanto em suas relações comunicativas, lógica interna estabelecida pelos participantes na estruturação da atividade, quanto em relação à "atmosfera" que se desenvolve durante a vivência em suas multiplicidades: naturais, sóciohistóricas, emocionais e arquetípicas. (Gomes-da-Silva et al., 2014, p.17).

Isso minimiza o empobrecimento da compreensão do jogo pelo exclusivo viés biodinâmico, considerando "seus condicionantes físicos, suas propriedades técnicas, suas motivações psicológicas e suas capacidades motoras" (Gomes-da-Silva, 2011, p. 18). Incluímos a importante dimensão da movimentação dos jogadores, mas também consideramos as condutas que entram no jogo. Os hábitos realizados durante as ações internas (que podem assumir características irrefletidas e/ou criativas) são muito valiosos, assim como as posturas táticas para os avanços nas tomadas de decisão e nas interações que se fazem durante os jogos. Entendemos que as ações realizadas são de extrema importância para os avanços do próprio jogo, haja vista que "cada jogador é observador e observado durante o jogo" (Ramos et al., 2004, p. 21).

No decorrer do jogo, podemos fazer algumas "leituras" de nós mesmos e do adversário que está à nossa frente. Essas "leituras" geram comunicações que resultarão em estratégias de interações (cooperaçãooposição), favorecendo melhores tomadas de decisão e posicionamentos mais inteligentes, pois, como enuncia Parlebas (1988), as decisões e as estratégias são provenientes das possíveis leituras corporais entre os jogadores. Portanto, essas interações partem da lógica interna.

A relevância deste estudo se justifica porque consideramos as ações dos jogadores como possíveis aprendizagens sob a ótica comunicativa. 
Os alunos podem tomar decisões que os ajudem a pensar em estratégias que facilitem sua comunicação com os companheiros e os adversários no contexto em que estão inseridos, sem que se restrinjam aos fundamentos técnicos de um jogo esportivo ou a uma regra estabelecida e/ou imutável de um jogo tradicional-popular.

É preciso que os educandos deem respostas às situações, em termos de adequação ao jogo, com vistas às necessidades espaciais, temporais, materiais e pessoais. Isso se concretiza a partir do momento em que se possibilita o conhecimento do mundo do jogo que cerca os alunos, fomentando o diálogo e o consenso entre eles sobre as regras e os espaços, o que contribui para melhorar a comunicação na tomada de decisão.

\section{Problematizando o jogo na escola}

Iniciamos nossa problematização com base em Santos (2012), que afirma não bastar ter um entusiasmo ingênuo na utilização do jogo na escola - em nosso caso, o uso do jogo tradicional-popular - sem definir claramente os objetivos pedagógicos. Parlebas (2013) acrescenta as temíveis dificuldades em estudar os jogos tradicionais, por um lado, a difícil coleta de dados em campo e, por outro, os obstáculos conceituais e metodológicos. Não obstante, ainda temos que lidar com o abandono de certos jogos tradicionais-populares ou as qualificações como "jogos inferiores" que objetivam preparar para os jogos "superiores", ou seja, os esportes propriamente ditos.

Contudo, suspeitamos da relevância dos jogos tradicionais-populares principalmente por sua permanência na história como partícipes da cultura lúdica. Esses jogos têm o potencial de flexibilizar nomes e regras, sem perder seu núcleo fundamental. Muitas vezes, são simples de jogar, porém, complexos nas ações que exigem em relação ao espaço, ao objeto e aos jogadores (companheiros e adversários).

Diante desse cenário, afirmamos nossa compreensão do jogo partindo da pedagogia da corporeidade (Gomes-da-Silva, 2005; 2012b) - o compromisso é investigar o jogo, nesse caso, o tradicional-popular, buscando discutir a conduta comunicativa dos jogadores: as decisões elaboradas mediante as necessidades das contínuas circunstâncias criadas pelo próprio jogo. Essas investigações estão implicadas numa pedagogia que oriente o modo de tratamento do jogo tradicional-popular no contexto educativo, como situação pautada na livre decisão de ação, para gerar uma aprendizagem significativa. A aprendizagem será significativa se houver produção de linguagem, ou seja, se as interações desenvolvidas no jogo problematizarem os esquemas cognitivo-motores adquiridos e exigirem novos hábitos de ação, menos reprodutores dos hábitos dominantes e mais inventivos, do ponto de vista cultural.

Portanto, quanto mais a metodologia de ensino valorizar as problematizações das situações novas, mais interações, comunicações e 
linguagens serão produzidas no jogo. Assim, a pedagogia da corporeidade orienta os jogos nas aulas de educação física para produção de nova linguagem do movimento humano. Gomes-da-Silva (2011, p. 89) assevera que, "continuamente, no mover-se, formam-se novos nós de significação, novas aprendizagens, reorganizações do esquema-corporal". Com isso, geram-se novas estratégias, combinações, gestos, movimentações e novas tomadas de decisão durante os jogos.

Agregamos a essa perspectiva o sistema praxiológico de Parlebas (2001), segundo o qual o jogo tradicional-popular se apresenta como um jogo de cooperação e de oposição, do ponto de vista da interação. Quando sociomotriz, o ato de jogar se caracteriza por ações comunicativas e contracomunicativas, culminando numa interpretação constante das mensagens dirigidas pelos companheiros e/ou adversários. São jogos complexos não só por ultrapassarem o previsível, até porque não são implicados na totalidade da previsibilidade, mas também, conforme alerta Ribas (2002, p. 66), pela dinâmica da lógica interna, já que "as informações relativas à lógica interna da atividade irão enriquecer o universo dessa prática, consequentemente, melhorando a possibilidade de prever, antecipar as ações e criar estratégias".

De modo que não é o jogar por jogar, no cumprimento das regras já estabelecidas, o melhor tratamento pedagógico, pois essa simplificação impede a produção de algo muito maior, que é a linguagem do movimento humano. Refletir a linguagem e o movimentar-se humano como diálogo com o mundo é uma das poucas possibilidades que ainda nos restam para uma melhor compreensão de quem somos e para ter, a partir deles, uma melhor consciência do mundo em que vivemos. Porém, até mesmo essas formas de expressão humana, praticamente, só se manifestam em forma da mera repetição, memorização ou cópia (Kunz, 2004).

Essa crítica de Kunz (2004) aos processos pedagógicos tradicionais corrobora os estudos de Carvalho e Oliveira (2014, p. 4), ao afirmarem que é "no jogo e por meio do jogo que a criança é capaz de atribuir significados diferentes aos objetos, desenvolver a sua capacidade de abstração e começar a agir independentemente daquilo que vê, operando com os significados diferentes da simples percepção dos objetos".

Por isso, a situação de movimento para a pedagogia da corporeidade é o epicentro da aprendizagem, porque é nessa relação da movimentação dos jogadores com a dada circunstância que a produção de sentido se manifesta nas inventivas tomadas de decisão dos alunos (Gomes-da-Silva, 2014; Gomes-da-Silva et al., 2014). A adaptabilidade do discente ao jogo se torna importante à medida que ele se adequa à sua peculiaridade. Isso implica a oportunidade que os indivíduos possuem para resolver problemas, investigar e descobrir a melhor jogada, refletir e analisar as regras, estabelecendo relações entre os elementos do jogo (Carvalho; Oliveira, 2014).

Lagardera e Lavega (2008) entendem que o próprio jogo exige que os participantes adaptem suas condutas singulares às características 
dele. Quando um jogador logra consegui-la, suas possibilidades de render bem mais nesse jogo aumentam - render mais significa, a partir das regras estabelecidas, potencializar as ações para que todos e cada um dos participantes lhes deem vida, que se coloquem à disposição de suas condutas motrizes singulares. A ação é constante, e a conduta, flutuante e particular.

Enfocamos as interações que ocorrem entre os alunos durante as aulas de educação física na medida que utilizam com mais frequência determinadas ações em função dos objetivos do jogador ou dos jogadores. "É muito distinto o uso que os jogadores fazem dessas ações. Isso gera dinâmicas muito diferentes em um mesmo jogo, dependendo de quem sejam os jogadores" (Largadera; Lavega, 2008, p. 71). Por isso, estamos associando o jogo na perspectiva da interação: a comunicação, no tocante aos hábitos adquiridos, caracterizando-se por um estilo, uma maneira de realizar uma tarefa no jogo.

Delimitando o objeto de estudo, escolhemos os jogos tradicionaispopulares para nossa discussão porque, na classificação praxiológica de Parlebas (2001), eles se enquadram nos sociomotrizes, caracterizados pelas situações em que o participante interage com os demais (Lavega, 2008). Esse aspecto do movimento que comunica, nas relações com o ambiente, objetos e jogadores, é relevante no que se refere ao jogo tradicional-popular. O conhecimento praxiológico visa desvendar essa lógica interna do jogo e seus pormenores internos, ou seja, "procura tratar das estruturas em funcionamento, das estruturas profundas e distintas que são significativas para compreensão do jogo" (Ramos et al., 2004, p. 19).

Levando em consideração toda a lacuna pedagógica no ensino dos jogos tradicionais-populares na educação física escolar e diante da relevância deles destacada anteriormente, resolvemos apresentar uma dupla abordagem teórica da comunicação do jogo, por meio do instrumental de interpretação da lógica interna, pertencente à praxiologia motriz, e da analítica existencial do movimento, pertencente à pedagogia da corporeidade.

\section{Jogo tradicional-popular: conceitos e perspectivas para aprendizagem}

Vimos que o jogo tradicional-popular, quando problematizadas suas ações interativas na tomada de decisão, é um possibilitador de novas aprendizagens na escola. Contudo, como ainda não houve a apresentação dos conceitos, faremos isso nesta seção. Iniciemos explicando o porquê da escolha do termo tradicional-popular em detrimento do tradicional ou do popular apenas. Segundo Araújo e Mendes (2007, p. 23),

[...] definir jogo tradicional e popular não é tarefa fácil, visto que muitos autores nem sequer distinguem jogo popular de jogo tradicional. Contudo, é importante clarificar as grandes diferenças existentes entre os termos popular e tradicional.

Kishimoto (2009) detém-se aos jogos tradicionais infantis, que 
guardam a produção cultural de um povo em certo período histórico e estão sempre em transformação, incorporando criações anônimas das gerações que vão se sucedendo. Segundo a autora, o jogo tradicional infantil assume características de anonimato, tradicionalidade, transmissão oral, conservação, mudança e universalidade. Assim, ele tem a função de perpetuar a cultura infantil e desenvolver formas de convivência social.

Para Lavega (2000), o jogo popular pertence ao povo, às pessoas do lugar, cujas características, crenças e estilos de vida estão incorporados em seu cotidiano. Já o jogo tradicional se caracteriza pelo processo de transmissão entre gerações e grupos de pessoas e tem continuidade durante determinado tempo histórico. O autor finaliza seu raciocínio, depois dessas considerações, e chama os jogos conhecidos e representados em um lugar ou época determinada de populares e/ou tradicionais, em virtude dessa combinação entre representação (muito praticado) e tempo (processos de transmissão entre diversas gerações e grupos de pessoas). O Quadro 1 apresenta alguns termos a serem considerados no que concerne ao jogo.

\section{Quadro 1- Conceito de Jogo Popular-Tradicional}

\begin{tabular}{|l|l|}
\hline \multicolumn{2}{|c|}{ Termos a considerar } \\
\hline \multicolumn{1}{|c|}{ Jogo popular } & \multicolumn{1}{c|}{ Jogo tradicional } \\
\hline Representativo de um local & $\begin{array}{l}\text { Quando há um hábito de processo de } \\
\text { transmissão entre várias gerações }\end{array}$ \\
\hline $\begin{array}{l}\text { Praticado de acordo com o estilo de } \\
\text { vida de determinada cultura }\end{array}$ & $\begin{array}{l}\text { Jogo conhecido e praticado por um } \\
\text { período considerável de tempo }\end{array}$ \\
\hline \multicolumn{2}{|c|}{ Jogo popular-tradicional } \\
\hline $\begin{array}{l}\text { Quando o jogo possui essa dupla qualidade: atravessou gerações e é represen- } \\
\text { tativo de um grupo social }\end{array}$ \\
\hline
\end{tabular}

Fonte: Adaptado de Lavega (2000).

De acordo com Santos (2012), comumente três termos são utilizados para classificar o jogo: popular, folclórico e tradicional. A autora esclarece que tais expressões acabam por gerar certa dificuldade no entendimento de professores e alunos sobre a essência de cada um deles. Assim, conforme suas pesquisas, os jogos tradicionais, os populares e os folclóricos são o retrato de uma época e de um local e, mesmo com as alterações que sofrem com o passar do tempo, continuam sendo jogados por diferentes populações. A tradição do jogo se reflete nas expressões da cultura popular e da identidade cultural de uma sociedade. O jogo, como tradição, ocorre quando o conhecimento sobre ele se perpetua na memória lúdica de um grupo social. Segundo Parlebas (2013, p. 14), 
[...] o jogo tradicional é, então, um jogo motor não institucionalizado que se apoia em três critérios objetivos específicos precisos: uma situação motriz, um sistema de regras e uma competição ou uma ritualização.

O autor assevera que, como todo fenômeno social, o jogo evolui e se transforma ao longo dos anos.

Mesmo já tendo representado um fenômeno socialmente importante nos séculos passados, alguns jogos tradicionais perderam seu brilho e hoje estão totalmente deixados na sombra. Eles aparecem em defasagem e não mais percebidos como portadores de valores do momento. É também por essa razão que os jogos se revestem de interesse aos olhos dos pesquisadores: os comportamentos que eles encorajam, a lógica interna que eles ilustram, correspondem às esperas, às aspirações e às normas da sua época. (Parlebas, 2013, p. 14).

Ao irmos ao encontro dos jogos tradicionais-populares, enaltecemos a importância dos jogos, suas regras, as condutas a partir das leis de funcionamento, a cultura presente neles e as possíveis aprendizagens pelo âmbito da comunicação. Isso implica a existência de regras e de ganhadores e perdedores quando da sua prática. É uma característica do ser suficientemente socializado, que pode, portanto, compreender uma vida de relações mais amplas (Freire, 2005).

Dialogando com a teoria praxiológica, o jogo tradicional-popular pode ser psicomotriz, um jogo individual, sem a interação com o outro; e sociomotriz, que se caracteriza pela interação com o outro como oposição (o movimento do praticante sofre interferência - e interfere - no movimento do adversário), como cooperação (o movimento do praticante sofre interferência - e interfere - no movimento do companheiro), ou ainda como prática de interação que conjuga a oposição e a cooperação (o movimento do praticante sofre interferência - e interfere - no movimento do adversário e no do companheiro), de acordo com Ribas (2004).

Vemos como imprescindível a análise do jogo tradicional-popular com regras, pois "a regra é a ordem posta em nossos atos, uma ordem subjetiva, aquela que eu ponho, para facilitar o jogo, nos meus atos e pensamentos" (Chateau, 1987, p. 62). É na ação diante da regra que está posta que o aluno pode tomar suas decisões oriundas das situações que acontecem no jogo, ou seja, a regra diz o que pode e o que não pode ser realizado. Largadera e Lavega (2008, p. 57) reforçam a importância do papel da regra no jogo afirmando:

As regras condicionam de tal forma seu modo de ser, que todos os componentes, que lhes outorgam vida no momento que são colocados em prática, relacionam-se entre eles de acordo com um modo bastante peculiar, segundo uma ordem estabelecida na convenção que antecede a sua origem. Essa especialíssima conjunção determina sua estrutura, ou seja, a maneira singular de relacionarem-se uns componentes com os outros.

A convenção do jogo é explícita mediante a regra, que estabelece como se deve fazer ou como convém realizar determinada ação, ou seja, o modo 
com que convém esta ou outra ação. Toda convenção ou contrato lúdico implica a enumeração de uma série de regras que definem as condições em que devem se realizar. Essa tríade regra-comunicação-ação é que favorecerá avanços nas interações e nas linguagens durante os jogos, por ser a forma mais avançada do jogo, por se tratar de uma possibilidade de realizar as formas mais sofisticadas do jogo de regras (Freire, 2005). Conhecendo as regras, podemos nos comunicar melhor, e isso resulta em novas ações com os outros jogadores (companheiros ou adversários).

O jogo é, antes de tudo, um sistema de regras; esse sistema define a estrutura e o modo de funcionamento da atividade, ou seja, sua lógica interna. O estudo dos jogos motrizes consistirá, em sua grande maioria, em colocar a descoberto as consequências acarretadas por essa lógica motriz sobre as representações coletivas ligadas a cada jogo tradicional e a cada esporte. (Parlebas, 2013, p. 13).

No jogo com regras, logo, o sujeito não age isoladamente, mas se orienta junto com os outros. Na perspectiva da pedagogia da corporeidade, esses outros não significam apenas os demais humanos, mas também o espaço, o tempo e os objetos. Entender nossa ação dentro do jogo, como o encontro com toda a circunstância, implica percebê-la como configuração do modo de existir, portanto, corporeidade, diria Gomes-da-Silva (2012a). E nessa analítica existencial da movimentação que passamos a compreender tanto o funcional do jogo como sua subjetivação. Nossas ações e inações, junto com as dos demais, tornam o meio lúdico um ambiente de comunicação que exige contínuas tomadas de ação.

Nos jogos tradicionais de competição especialmente, as circunstâncias apresentam-se com obstáculos a serem vencidos, e nesse confronto social o participante lança mão de seus recursos cognitivo-motores, submete-se a regras exteriores e toma sua decisão de ação. Sendo assim, o jogo tradicional-popular caracteriza-se como flexível, porque suas regras podem ser modificadas, desde que tenha havido acordo coletivo. Essa condição faz desse jogo uma prática de linguagem integrada ao ambiente que a criou, podendo ser recriado constantemente, conforme as novas variantes (Cervantes, 2005).

O jogo tradicional não é apenas jogo. Quando um jogo tradicional é realizado, importa tanto o que o cerca como o jogo em si. Da própria escolha de jogadores, como as atitudes e relação dos mesmos, assim como a linguagem utilizada, tudo faz parte da encenação, sendo importante para contar e analisar o próprio jogo. (Cervantes, 2005, p. 112).

O jogo tradicional-popular é importante porque se constitui num excelente mecanismo contra uma educação excessivamente técnica, estimula a criatividade e permite destacar seus valores sociomotores, independentemente do jogador que atua. O mais interessante é a ação do jogador em certa situação e suas consequências para o funcionamento do jogo, que é um elemento indispensável para o desenvolvimento das aprendizagens significativas. Nessa perspectiva, o jogo tradicional-popular 
pode funcionar como um facilitador de procedimentos, habilidades, formas de relação, valores, atitudes, formas de pensar, gestos, entre outros.

A flexibilidade e a multiplicidade do jogo tradicional-popular possibilitam a compreensão da experiência motriz ao assimilar e resignificar os hábitos culturais. O modo como o jogador habita o tempo e o espaço do jogo é em que consiste a analítica existencial do movimento, pois, de acordo com as ações, ocupações e posições no espaço/tempo do jogo, o jogador revela seu sistema de significação aplicado às situações existenciais imediatas. Segundo a pedagogia da corporeidade (Gomesda-Silva, 2011; 2012a; 2014), o mundo do jogo é sempre mundo vivido, a ação ou inação é sempre um gesto significante para quem, individual ou coletivamente, realizou-a.

Pela lógica interna da praxiologia motriz, as manifestações dos jogos tradicionais-populares são analisadas pelas formas como os jogadores interagem com seus companheiros e adversários e se relacionam com o espaço e o terreno de jogo diferentemente. Além disso, cada jogo pode solicitar um objeto lúdico distinto, como bolas, bastões e/ou raquetes. Cada atividade lúdica ostenta um universo único de ações motrizes, produto da singular lógica exigida pelo jogo (Ramos et al., 2004).

Essa rede de interação motriz no jogo proporciona quatro tipos de interações possíveis, segundo o estatuto sociomotriz dos jogadores, conforme Largadera e Lavega (2008). As relações ou interações motrizes entre os participantes podem ser cooperativas, quando se estabelece uma comunicação motriz de colaboração, e de oposição ou antagônicas, denominadas por Parlebas (2001) de processos de contracomunicação motriz. Já o espaço de jogo normalmente está demarcado por linhas que o limitam e condicionam, como as laterais, de fundo, do centro e do gol, pelas quais se pode passar e nas quais se pode pisar ou não, dependendo da circunstância do jogo e da modalidade que corresponda a um jogador de uma equipe ou de outra.

Nas relações do jogador com os objetos ou implementos que intermedeiam o enfrentamento, as regras estabelecem a forma como os jogadores têm que se relacionar com os objetos lúdicos e como deverão se ajustar ao tempo de jogo. Existem jogos/esportes em que os participantes dispõem de determinada limitação temporal para realizar as ações.

Conhecer o estatuto sociomotriz de todo jogo ou modalidade esportiva se converte, assim, em um procedimento básico para desvelar aspectos importantes da lógica do jogo, de sua coerência interna. Sabemos as condições com que cada participante pode jogar, visto que nem todos os jogadores podem realizar uma ação motriz da mesma forma. Cada estatuto define uma determinada maneira de atuar, de realizar um papel, função ou atividade específica. (Largadera; Lavega, 2008, p. 78).

Ressalte-se, porém, que não basta conhecer as leis que regem um jogo tradicional-popular, suas características e as relações que emergem numa ação motriz, é preciso, também, agir nele utilizando outras formas de comunicação direta: as ações gestuais. Os comportamentos do participante ganham sentido na relação com o ambiente, com seus parceiros e/ou com 
seus adversários. Segundo Ramos et al. (2004), as condutas motrizes produzem grande número de comunicações não verbais, que Parlebas considera como gestemas e praxemas, as quais favorecem as interpretações dos comportamentos dos sujeitos em situação de jogo. "Esse sistema de signos impõe a cada jogador decifrar códigos corporais como: pré-ações, antecipações, os sinais dos companheiros e adversários e também os imprevistos, os índices e obstáculos que o meio físico oferece" (Ramos et al., 2004, p. 20). Os gestemas são atos especificamente motrizes e os praxemas são representados pelos comportamentos estratégicos dos participantes do jogo.

Desse modo, a lógica interna e a analítica existencial oferecem as múltiplas maneiras de investigar o jogar, aproximando o movimento no jogo mediante um relato das interações com jogadores e meio, bem como com o modo de habitar o tempo "vivido" do jogo, analisando a tendência dos gestos e a sucessão dos movimentos localizados num espaço de ação, dependendo do contexto empregado.

Com isso estamos afirmando que os brincantes, ao se comunicarem corporalmente durante o jogo, participam de uma mesma experiência, compartilham a mesma visão de mundo, mesmo com aqueles que se apresentam como adversários. Nas práticas motoras, os jogadores participam de um mesmo circuito de comunicação e se envolvem num vínculo de convivência. E esse vínculo implica os sujeitos naquilo que gesticulam entre si, os seus movimentos não estão apenas dentro do jogo, mas pertencem ao jogo e constituem o jogo. (Gomes-da-Silva, 2011, p. 97).

A investigação pela analítica existencial recai nas escolhas e atitudes dos jogadores: por que utilizam certa ação com frequência e não outras? Por que permanecem com os mesmos hábitos motrizes, sem reconhecêlos ineficientes? O aluno precisa entrar em contato com outras ações, habituar-se a considerar o outro como partícipe em jogos de cooperaçãooposição e o quanto suas ações culminam na evolução da compreensão e da aprendizagem ou não do grupo durante os jogos.

Para isso, os movimentos dos jogadores, previsíveis ou não, prestam-se à possibilidade de desvelar seu ser para si mesmo e para o outro. É possível compreender-se e compreender o outro nos movimentos realizados nos jogos (Gomes-da-Silva, 2012b; Gomes-da-Silva et al., 2014). Portanto, sugere-se que os jogadores interpretem (Hernandez Moreno; Rodriguez Ribas, 2004) essas informações gestuais e ações motrizes de si mesmos e dos outros para um raciocínio prévio nas tomadas de decisão e na sequência das ações durante os jogos.

Esse entendimento do jogo tradicional-popular, no contexto escolar, abre o acesso a outros tratamentos pedagógicos, como: conhecimento das próprias possibilidades e limitações no jogo; conhecimento da identificação e interiorização das regras do jogo; conhecimento dos diferentes ambientes de aprendizagem no jogo, conforme papéis e posições - ataque e defesa (Cervantes, 2005).

Soares, Gomes-da-Silva e Ribas (2012) analisaram alguns jogos tradicionais-populares em uma praça de um bairro da zona oeste de 
João Pessoa e nos trazem informações importantes que reforçam o que acreditamos no tocante a esses jogos. Segundo os autores, os jogos tradicionais, devido a sua popularidade e possibilidade de flexibilização de regras, negociação dos conflitos, adaptação dos jogadores-espaçoimplemento, poderiam estar sendo valorizados pelos professores de educação física na escola como fonte de informação para construir conhecimentos sobre cidadania-em termos de participação social e política, responsabilidade ética e civil de solidariedade e cooperação - e para ensinar e apreciar criticamente a própria cultura de movimento em contraponto a cultura esportiva midiática. Portanto, recomendam a valorização dos jogos tradicionais-populares na educação física escolar.

Sousa Cruz (2014), em estudo recente sobre a aprendizagem interativa e cognitiva do baleado e da barra-bandeira nas aulas de educação física escolar, percebeu que, por meio dos jogos tradicionais-populares, nas operações de constatar os erros, refletir sobre as possibilidades e transformar a ação, os jogadores aprenderam a tomar decisões menos precipitadas, mais inteligentes. Diante dos problemas oriundos das inúmeras situações no jogo, aprenderam a agir de modo coletivo e estrategicamente refletido, por exemplo, a melhor hora de passar/arremessar, aproveitar as situações de desatenção, passar para salvar o companheiro, combinar a bola e perceber-se no jogo, entendendo o tempo de jogo nas situações oportunas e em marcações cerradas; e a melhor maneira de agir. Aprenderam a criar situações de interação vivendo o jogo, na observação e conduta de si e do outro. É o jogo se tornando rico pelas interações nas tomadas de decisão.

Por fim, ao aproximarmos essas duas teorias de interpretação do jogo, apresentamos o Quadro 2, que identifica e descreve os indicadores existenciais e praxiológicos que fundamentaram nossa discussão teórica. Além do mais, esse quadro fornece uma síntese esquemática que possibilita reaplicação em estudos posteriores sobre as inúmeras relações comunicativas do jogo, com suas consequentes aprendizagens comunicativas.

Pela lógica interna (da teoria praxiológica), entendemos a ação motriz dentro do jogo como uma rede de interações constantes, independentemente de quem o faz, favorecendo inúmeras tomadas de decisão, "leituras" gestuais, antecipações, cooperações (companheiros) e oposições (adversários), sugerindo que os jogadores interpretem essas informações gestuais e táticas de si mesmos e dos outros para um raciocínio prévio nas tomadas de decisão e na sequência das ações durante os jogos.

Pela analítica existencial do movimento (da teoria da pedagogia da corporeidade), compreendemos os jogadores ao se comunicarem no jogo, sua produção de linguagem, por meio da percepção do entorno, da assimilação da circunstância e da elaboração de ação inventiva ou reprodutiva para consigo mesmos e para com os adversários. Nas práticas motoras, os jogadores participam de um mesmo circuito de comunicação e se envolvem num vínculo de convivência. Esse vínculo implica os sujeitos naquilo que gesticulam entre si, portanto, sua movimentação não só está dentro do jogo, mas pertence a ele e o constitui. 


\section{Quadro 2 - Categorias Referentes à Interação no Jogo Tradicional- Popular: Analítica Existencial e Praxiologia Motriz}

\begin{tabular}{|c|c|c|}
\hline Categorias & \multicolumn{2}{|c|}{ Indicadores existenciais e praxiológicos } \\
\hline Modo deficiente & \multicolumn{2}{|c|}{ Comunicação com meio e implementos na ausência do outro semelhante. } \\
\hline Modo indiferente & \multicolumn{2}{|c|}{$\begin{array}{l}\text { Comunicação indiferente com meio, implementos e outro, numa atitude } \\
\text { de não se sentir tocado, de não oferecer comunicação. }\end{array}$} \\
\hline \multirow{2}{*}{$\begin{array}{l}\text { Modo primordial } \\
\text { Comunicação com meio, } \\
\text { implementos e outro de } \\
\text { duas formas (substitutivo e } \\
\text { anteposição) e modos: }\end{array}$} & \multirow{2}{*}{$\begin{array}{l}\text { Movimento substitutivo: } \\
\text { movimentação padronizada, } \\
\text { dependente, automatizada e } \\
\text { culturalmente repetitiva. }\end{array}$} & $\begin{array}{l}\text { Compreensão da regra: } \\
\text { memória, aceitação dos códigos } \\
\text { reguladores (tempo, espaço, } \\
\text { pontuação). }\end{array}$ \\
\hline & & $\begin{array}{l}\text { Tomada de decisão: } \\
\text { ter condutas estratégicas, errar } \\
\text { menos. }\end{array}$ \\
\hline \multirow{2}{*}{$\begin{array}{l}\text { a) Modo operatório - decisão, } \\
\text { decodificação, antecipação. } \\
\text { b) Modo coordenativo - } \\
\text { compreensão da regra, } \\
\text { aceitação dos códigos } \\
\text { reguladores (tempo, } \\
\text { espaço, pontuação); não } \\
\text { transgressão. }\end{array}$} & \multirow{2}{*}{$\begin{array}{l}\text { Movimento de anteposição: } \\
\text { resposta não padronizada, } \\
\text { consciência das limitações e } \\
\text { possibilidades, criativo/inventivo. }\end{array}$} & $\begin{array}{l}\text { Decodificação: } \\
\text { leitura gestual, atenção. }\end{array}$ \\
\hline & & $\begin{array}{l}\text { Antecipação: } \\
\text { capacidade de abstração e de } \\
\text { concentração. }\end{array}$ \\
\hline
\end{tabular}

Fonte: Adaptação de Sousa Cruz (2014) e Gomes-da-Silva (2014).

\section{Considerações finais}

A relação das duas teorias de apoio para compreender o jogo tradicional-popular consistiu na explicitação das interações no contexto do jogo e nos avanços nas tomadas de decisão. São essas interações que mobilizam uma mudança de hábito no jogador ao criar novas ações em anteposição ao modo repetitivo, o que possibilita ao jogador ações táticas que se sobressaem diante das situações-problema.

É nessa perspectiva da dupla interpretação do jogo, pela lógica interna (praxiologia motriz) e pela analítica existencial (pedagogia da corporeidade), que apontamos um caminho metodológico de aprendizagem do jogador. E na problematização das situações de movimento, por meio de variações nas regras, que se ensina ao jogador (individual e coletivo) buscar soluções inteligentes. A produção de soluções criativas diz respeito à prática de linguagem, da significação no jogo, cujas ações técnicas e táticas são produtoras e produtos da consciência da tomada de decisão.

As teorias que trouxemos e o diálogo que propusemos se aproximam no que concerne à valorização da ação do jogador, de suas condutas dentro do jogo, do modo como ele age nas situações, seja com companheiros e/ ou adversários, inseridos em um espaço de jogo. As interações ocorrem junto do entorno (jogadores, objetos, espaço). O modo como o jogador vive no tempo e no espaço do jogo é relevante do ponto de vista da conduta 
lúdica adotada, pois o ser-jogador se realiza na medida em que aprende a se posicionar e agir no espaço/tempo do jogo, dispondo de um sistema de significação adquirido e aplicando-o às situações existenciais nas ações.

Confirmamos, assim, a extraordinária função socializadora dos jogos tradicionais, funcionando como lugar adequado para as aprendizagens comunicativas e competências sociais, necessárias na sociedade do bemestar do século 21. Desse modo, destacamos a importância de se continuar investigando o jogo tradicional-popular pelos pressupostos da lógica interna (Parlebas, 2001; 2013) e da analítica existencial (Gomes-da-Silva, 2001; 2011; 2012a; 2014), que é o paradigma da comunicação.

Assim sendo, ampliam-se as possibilidades de exploração do aprendizado dos jogadores nas dimensões sociais e comunicativas, cognitivas, perceptivo-motoras e emotivas. Suspeitamos que esse encontro das teorias (pedagogia da corporeidade; praxiologia motriz), diante das suas especificidades, aproximações e distanciamentos, evidencia a situação de movimento do jogo como espaço de formação humana e cultural. Essas abordagens teóricas compreendem o funcional e o subjetivo do jogo ao refletirem sobre as ações dos sujeitos, e o que delas se sobressai criativamente no tocante aos elementos previamente estabelecidos para análise. Concluímos, portanto, em defesa do tratamento pedagógico dos jogos tradicionais-populares na construção do sujeito criativo, que, em meio às situações de oposição-cooperação e às tomadas de consciência, eles desenvolvem a vivência comunicativa como prática de linguagem.

\section{Referências bibliográficas}

ARAÚJO, P. C.; MENDES, N. M. C. O jogo da bola de aro em São Miguel de Machede. Lousã: Tipografia Lousanense, 2007.

BROUGÉRE, G. Jogo e educação. Porto Alegre: Artes Médicas, 2002.

CALLOIS, R. Os jogos e os homens: a máscara e a vertigem. Lisboa: Cotovia, 1990.

CARVALHO, L. R. R; OLIVEIRA, F. N. Quando o jogo na escola é bem mais que jogo: possibilidades de intervenção pedagógica no jogo de regra set game. Revista Brasileira de Estudos Pedagógicos, Brasília, DF, v. 95, n. 240, p. 431-455, maio/ago. 2014.

CERVANTES, C. T. Aprendizagem de valores sociais através do jogo. In: MURCIA, J. A. M. (Org.) Aprendizagem através do jogo. Porto Alegre: Artmed, 2005.

CHAteAU, J. O jogo e a criança. São Paulo: Summus, 1987. 
FREIRE, J. B. O jogo: entre o riso e o choro. Campinas: Autores Associados, 2002.

FREIRE, J. B. Educação de corpo inteiro: teoria e prática da educação física. São Paulo: Scipione, 2005.

FREIRE, J. B; SCAGLIA, A. J. Educação como prática corporal. São Paulo: Scipione, 2007.

GOMES-DA-SILVA, P. N. Por uma ontologia do movimento comunicativo. In: GUEDES, O. C. Atividade física e esportes: contextos e perspectivas evolutivas. João Pessoa: Unipê, 2001.

GOMES-DA-SILVA, P. N. Jogo, cultura e pulsão: uma semiótica dos brinquedos e dos brincantes. In: VITA, I. B.; ANDRADE; F. C. B. (Org.). (Des)fiando a trama: a psicanálise nas teias da educação. São Paulo: Casa do Psicólogo, 2005. p. 77-96.

GOMES-DA-SILVA, P. N. O jogo da cultura e a cultura do jogo: por uma semiótica da corporeidade. João Pessoa: Ed. UFPB, 2011.

GOMES-DA-SILVA, P. N. A corporeidade do movimento: por uma análise existencial das práticas corporais. In: HERMIDA, J. F.; ZOBOLI, F. Corporeidade e educação. João Pessoa: Ed. UFPB, 2012a.

GOMES-DA-SILVA, P. N. A potência educativa do jogo da bola de gude. In: CAMINHA, I. (Org.). Inconsciente e educação. Curitiba: CRV, 2012b. p. 105-134.

GOMES-DA-SILVA, P. N. Pedagogia da corporeidade: o decifrar e o subjetivar na educação. Tempos e espaços em educação, São Cristóvão, SE, v. 7, n. 13, maio/ago. 2014.

GOMES-DA-SILVA, P. N.; ANTÉRIO, D.; SCHUlZE, G. B.; CRUZ, R. W. $S$. Descrevendo a corporeidade: implicações educativas a partir da ginga do brasileiro no futebol e na dança. Educação: teoria e prática, Rio Claro, SP, v. 24, n. 46, p. 97-119, maio/ago. 2014.

GOMES-DA-SILVA, P. N.; CAVALCANTI; K.; HILDEBRANDT, R. A poética dos gestos dos jogadores. Rev. Bras. Ciências do Esporte, Porto Alegre, RS, v. 27, n. 2, p. 105-120, 2006.

HERNANDEZ MORENO, J; RODRIGUES RIBAS, J. P. La praxiologia motriz: fundamentos y aplicaciones. Barcelona: Inde, 2004.

HUIZINGA, J. Homo ludens: o jogo como elemento da cultura. São Paulo: Perspectiva, 1996 
KISHIMOTO, T. M. Jogos infantis: o jogo, a criança e a educação.

Petropólis: Vozes, 2009.

KUNZ, E. (Org.). Didática da Educação Física. 2. ed. Ijuí: Unijuí, 2004. LAGARDERA, O.; LAVEGA, P. Fundamentos da praxiologia motriz. In: RIBAS, J. F. M. (Org.). Jogos e esportes: fundamentos e reflexões da praxiologia motriz. Santa Maria: Ed. UFSM, 2008. p. 45-80.

LAVEGA, P. Juegos y deportes populares tradicionales. Barcelona: Inde, 2000.

LAVEGA, P. Classificação dos jogos, esportes e as práticas motrizes. In: RIBAS, J. F. M. (Org.). Jogos e esportes: fundamentos e reflexões da praxiologia motriz. Santa Maria: Ed. UFSM, 2008. p. 81-104.

LAVEGA, P. Os jogos tradicionais como patrimônio cultural mundial. In: MARIN, E. C.; RIBAS, J. F. M. (Org). Jogo tradicional e cultura. Santa Maria: Ed. UFSM, 2013.

MARIN, E. C.; RIBAS, J. F. M. (Org). Jogo tradicional e cultura. Santa Maria: Ed. UFSM, 2013.

MARIN, E. C.; RIBAS, J. F. M.; PARLEBAS, P.; STEIN, F.; CRESTANI, A. de V. Jogos tradicionais no estado do Rio Grande do Sul: manifestação pulsante e silenciada. Movimento, Porto Alegre, v.18, n. 3, p.73-94, jul./ set., 2012 .

MURCIA, J. A. M (Org.). Aprendizagem através do jogo. Porto Alegre: Artmed, 2005.

MURCIA, J. A. M; GARCÍA, P. L. R. Do jogo ao esporte. In: MURCIA, J. A. M. (Org.). Aprendizagem através do jogo. Porto Alegre: Artmed, 2005.

ORTIZ, J. P. Aproximação teórica à realidade do jogo. In: MURCIA, J. A. M. Aprendizagem através do jogo. Porto Alegre: Artmed, 2005. p. 9-28.

PARLEBAS, P. Elementos de sociologia del deporte. Málaga: Junta de Andalucia/ Universidade Internacional Deportiva de Andalucia, 1988.

PARLEBAS, P. Juegos, deporte y sociedad: léxico de praxiologia motriz. Barcelona: Paidotribo, 2001.

PARLEBAS, P. Jargão e linguagem científica. In: RIBAS, J.F. M. (Org.). Jogos e esportes: fundamentos e reflexões da praxiologia motriz. Santa Maria: Ed. UFSM, 2008. 
PARLEBAS, P. Prefácio. In: MARIN, E. C.; RIBAS, J. F. M. (Orgs). Jogo tradicional e cultura. Santa Maria: Ed. UFSM, 2013.

PAVÍA, V. Jogo. In: GONZALEZ, F. J. ; FENSTERSEIFER, P. E. (Orgs.) Dicionário crítico de educação física. 3. ed. rev. e ampl. Ijuí: Ed.Unijuí, 2014.

PIAGET, J. A formação do símbolo na criança: imitação, jogo e sonho imagem e representação. Rio de Janeiro: LTC, 1990.

PIAGET, J. O juízo moral na criança. 2. ed. SP: Summus, 1994.

RAMOS, J. R. S. Queimado: um jogo tradicional desvendado pelas impressões praxiológicas. In: RAMOS, J. R. S. et al. (Orgs.). Praxiologia Motriz no Brasil. O discurso da ação motriz no Brasil: apontamentos para análise praxiológica em diferentes jogos, práticas corporais e brincadeiras. Niterói: Faculdades Integradas Maria Tereza, 2004.

RAMOS, J. R. S.; SILVA, F. V. da; CHAGAS, L. S.; T. Neto, Walfredo Cantalice da. 'O pique da cachoeira' e os fundamentos da praxiologia em um ambiente escolar na Ilha Grande. In: RAMOS, J. R. S. et al. Praxiologia motriz no Brasil: o discurso da ação motriz no Brasil. Niterói: Erthal, 2004.

REVERDITO, R. S.; SCAGLIA, A. J. Pedagogia do esporte: jogos coletivos de invasão. SP: Phorte, 2009.

RIBAS, J. F. M. Contribuições da praxiologia motriz para a educação física escolar: ensino fundamental. 2002. $226 \mathrm{f}$. Tese (Doutorado em Educação Motora) - Faculdade de Educação Física, Universidade Estadual de Campinas, Campinas, 2002.

RIBAS, J. F. M. Copa do mundo de futebol: deu a lógica, praxiológica. In: RAMOS, J. R. S. et al. (Orgs.). Praxiologia motriz no Brasil. O discurso da ação motriz no Brasil: apontamentos para análise praxiológica em diferentes jogos, práticas corporais e brincadeiras. Niterói: Faculdades Integradas Maria Tereza, 2004.

RIBAS, J. F. M. Praxiologia motriz: construção de um novo olhar dos jogos e esportes na escola. Motriz, Rio Claro, v.11, n.2, p. 103-110, maio/ ago., 2005.

RIBAS, J. F. M.(Org). Jogos e esportes: fundamentos e reflexões da praxiologia motriz. Santa Maria, RS: Ed. UFSM, 2008.

SANTOS, G. F. L. Jogos tradicionais e a educação física. Londrina: Eduel, 2012 . 
SOARES, L. E. S; GOMES-DA-SILVA, P. N.; RIBAS, J. F. M. Comunicação motriz nos jogos populares: uma análise praxiológica. Movimento, Porto Alegre, v. 18, n. 3, p. 159-182, jul./set. 2012.

SOUSA CRUZ, R. W. FARIAS, G. de P.; ANTERIO, D.; SOARES, L. E. S.; OLIVEIRA, D. M. de; RIBAS, J. F. M.; GOMES-DA-SILVA, P. N. Interação e criação no jogo barra-bandeira: aprendizagem na perspectiva parlebasiana e winnicottiana. EFDeportes: Revista Digital, Buenos Aires, v. 19, n. 201, feb. 2015.

SOUSA CRUZ, R. W. Aprendizagens interativas e cognitivas em jogos tradicionais-populares nas aulas de educação física. 2014. 119 f. Dissertação (Mestrado em Educação) - Centro de Educação, Universidade Federal da Paraíba, 2014.

VYGOTSKY, L. S. A formação social da mente: desenvolvimento dos processos psicológicos superiores. São Paulo: Martins Fontes, 1996. WINNICOT, D. O brincar e a realidade. Rio de Janeiro: Imago, 1975.

Recebido em 26 de novembro de 2014.

Solicitação de correções 27 de maio de 2015.

Aprovado em 3 de julho de 2015. 